УДК 657.01

DOI 10.31882/2311-4711.2019.25.13

\author{
Лысенко Юлия Андреевна \\ кафедра бухгалтерского учета и налогообложение \\ Российский экономический университет имени Г.В.Плеханова, \\ Российская Федераџия, г. Москва, 117997, Стремянный пер., 36 \\ E-mail: ju.lis@list.ru
}

\title{
ЦИФРОВИЗАЦИЯ ЭКОНОМИКИ И ХВRL В ОБМЕНЕ ФИНАНСОВОЙ ИНФОРМАЦИЕЙ В БИЗНЕС-СООБЩЕСТВЕ
}

\begin{abstract}
Аннотация. В статье проведено исследование особенностей развития цифровой экономики в Российской Федерации и внедрения формата XBRL для обмена деловыми данными в бизнес-сообществе и регуляторами. По результатам исследования была подтверждена актуальность и востребованность цифровой экономики. Определено, что цифровая экономика представляет собой модель взаимодействия всех участников экономических процессов, основанная на использовании современных электронных каналов связи и способов учета и хранения информации, с использованием электронного документооборота. Было отмечено, что передовые технологии, к которым относится XBRL, открывает новые возможности, предлагая новую модель, соответствующую изменяющимся потребностям обмена бизнес-информацией. Статья выполнена под научным руководством к.э.н., доцента Морозовой Т.В., кафедра бухгалтерского учета и налогообложения РЭУ им. Г.В. Плеханова.
\end{abstract}

Ключевые слова: цифровая экономика, цифровизация, XBRL, обмен финансовой информацией.

Введение. Сектор информационных технологий за последние двадцать лет сделал большой скачок вперед, помогая обществу, бизнесу и целым государствам совершенствоваться: оптимизировать издержки, создавать новые продукты и услуги, повышать качество жизни и т.д. [1,2]. Главными драйверами для цифровой экономики стали развитие интернета и электронной коммерции, которые открыли новые пути обмена информацией, продажи товаров и оказания услуг. Развитие цифровой экономики может идти по разным направлениям развития, в том числе, внедрения в практику обмена деловой и финансовой информации в формате XBRL $[3,4]$.

Методика. Цифровая экономика характеризуется активным использованием информационно-коммуникационных технологий в целях осуществления различных видов взаимодействий, в том числе юридически-значимых, между всеми участниками экономических процессов. Представленные направления развития цифровой экономики являются основными факторами роста производства практически во всех областях социально-экономической деятельности, что, безусловно, позволит обеспечить конкурентоспособность страны и на долгосрочной основе экономического роста и национального суверенитета, и экономической безопасности.

Основная часть. Потенциальный эффект ВВП
России за счет цифровизации экономики к 2025 году может составить от 4,1 до 8,9 трлн руб., или $19-34 \%$ от общего увеличения ВВП, сообщается в презентации McKinsey, представленной на форуме «Взгляд в цифровое будущее» $[5,7]$.

В мировой практике на сегодняшний день выделяется несколько ключевых направлений цифровизации. В технологическом развитии это:

1) широкое внедрение высокоскоростной беспроводной передачи данных;

2) дальнейшее развитие облачных технологий, стирание границ между различными игроками этого рынка и формирование единого интегрального «облачного пространства» [6];

3) создание сетевых платформ для наработки баз данных для обучения искусственного интеллекта;

4) дальнейший рост эффективности «больших данных» [8].

Все направления развития цифровизации могут эффективно поддерживать друг друга. Таким образом, отмечается актуальность и востребованность цифровой экономики для развития экономики в целом. Цифровая экономика представляет собой модель взаимодействия всех участников экономических процессов, основанная на использовании современных электронных каналов связи и способов учета и хранения информации, с использованием электронного документооборота [9]. 
С развитием цифровой экономики все большую роль приобретает совершенствование методов электронного обмена данными. А электронный обмен данных, в свою очередь, включает метод электронной коммуникации, который обеспечивает стандарты для обмена данными через любые электронные средства $[10,11]$.

В целях развития электронного формата обмена деловыми данными в бизнес-сообществе Банком России используется стандарт XBRL (eXtensible Business Reporting Language), который представляет собой открытый стандарт для представления финансовой отчетности, составленной в соответствии с МСФО, US GAAР и другими стандартами финансовой отчетности в электронном виде. Стандарт XBRL основан на языке разметки XML, модифицированном для целей создания унифицированного метода представления и обмена данными финансовой отчетности [12].

В противоположность традиционной отчетности, XBRL оперирует не формами, а базовыми показателями, сгруппированными в модели данных и позволяющими получить аналитическую информацию в различных разрезах. Представление отчетности в новом электронном формате XBRL стало обязательным для следующих участников финансового рынка:

- с 01.01.2018 - для страховых организаций и обществ взаимного страхования; лиц, осуществляющих функции центрального контрагента и некоторых других организаций;

- с 04.05.2018 - для акционерных инвестиционных фондов, управляющих компаний инвестиционных фондов, паевых инвестиционных фондов и негосударственных пенсионных фондов

Переход кредитных рейтинговых агентств и страховых брокеров на представление отчетности в формате XBRL запланирован на 2019 год; микрофи- нансовых организаций, специализированных депозитариев, кредитных потребительских кооперативов и жилищных накопительных кооперативов - на 2020 год; сельскохозяйственных кредитных потребительских кооперативов и ломбардов - на 2022 год [13].

Вместе с тем для технологической поддержки поднадзорных организаций в процессе формирования отчетности Банк России разработал два вида программного обеспечения, обеспечивающего конвертацию данных в формат XBRL и их валидацию перед отправкой в Банк России. Кроме того, российская юрисдикция XBRL (Центр XBRL) в настоящий момент разрабатывает программы сертификации для специалистов в области XBRL и программного обеспечения для работы с форматом XBRL, что позволит гарантировать качество программных продуктов и компетенцию экспертов $[14,15]$. При этом основными преимуществами от внедрения XBRL являются - повышение качества данных; прозрачность требований к отчетности; снижение стоимости обработки данных до 40\% за счет унификации технологического подхода; повышение скорости обмена данными; а также открытость и возможность международной интеграции.

Заключение. По результатам проведенного исследования было определено, что была подтверждена актуальность и востребованность цифровой экономики для развития экономики в целом. Определено, что цифровая экономика представляет собой модель взаимодействия всех участников экономических процессов, основанная на использовании современных электронных каналов связи и способов учета и хранения информации, с использованием электронного документооборота. Было отмечено, что передовые технологии, к которым относится XBRL, открывает новые возможности, предлагая новую модель, соответствующую изменяющимся потребностям обмена бизнес-информацией.

\section{Список использованных источников}

1. Брыкин A.B. Отчетность в формате XBRL: опыт подготовки.//Корпоративная финансовая отчетность. Международные стандарты. 2016. № 3. URL: http://finotchet.ru/articles/932/.

2. Морозова Т.В., Сафонова Э.Г., Калачева О.Н. Оценка влияния на таксономию МСФО-отчетности формата XBRL // Азимут научных исследований: экономика и управление. 2018. Т.7. №2 (23). С. 273-241.

3. Akhmadeev R.G., Kosov M.E. De-offshore process of the Russian economy as a way to control capital «escape» // Международный журнал гражданского и торгового права. 2016. № 1. С. 112-116.

4. Юдина Т.Н., Тушканов И.М. Цифровая экономика сквозь призму философии хозяйства и политической экономии // Философия хозяйства. - 2017. - № 1.

5. Erkus H., Chiu V. On the research contribution of XBRL literature - a bibliometrics fnalysis // Eurasian Journal of Business and Economics. 2014. № 7 (13), pp. 173-188.

6. Бабынина Л.С., Колесникова О.А., Похвощев В.А. Региональные проблемы занятости, уровня и качества жизни населения. М., 2007.

7. Шихатов П.И. Возможные пути оптимизации финансового учета в малых предприятиях // Вестник Международного института экономики и права. 2015. № 3 (20). С. 51-57. 
8. Морозова Т.В. Правовое регулирование государственной поддержки субъектов малого и среднего предпринимательства // Вестник АКСОР. 2012. № 4 (24). С. 47-52.

9. Депутатова Е.Ю., Ильяшенко С.Б. Вопросы изучения покупательского спроса и оценки емкости рынка // Экономика и предпринимательство. 2017. № 8-3 (85). С. 56-61.

10. Ващекина И. В., Ващекин А. Н. Применение риск-ориентированного подхода при организации противодействия отмыванию нелегальных доходов в российской практике // Наука и практика. 2018. № 3. С. 61-69

11. Горина Г.А., Ахмадеев Р.Г. Трансфертное ценообразование и новации налогового контроля // Справочник экономиста. 2013. № 3 (117). С. 14-25.

12. Дюжов А.В. Налоговая конкуренция и ее роль в повышении доходного потенциала бюджетов бюджетной системы РФ // В сборнике: Инновационное развитие Российской Экономики IX Международная научно-практическая конференция. РЭУ им. Г.В. Плеханова. РГНФ. 2016. С. 267-269.

13. Kosov M.E., Akhmadeev R.G. Improving tax management - real way of rasing budget income of Russia // Мировая экономика: проблемы безопасности. 2016. № 2. С. 68-72.

14. Кузнецов Н.В., Понкратов В.В., Котова Н.Е. Опыт использования института консолидированного налогоплательщика для стимулирования инвестиционной активности корпораций // Экономика и предпринимательство. 2018. - №10. - С. 991-995.

15. Понкратов В.В. Налоговая политика Российской Федерации в посткризисный период // Вестник Удмуртского университета. Серия Экономика и право. - 2012. - №2. - С. 51-56.

\author{
Lysenko Yuliya Andreevna \\ Department of Accounting and Taxation \\ Plekhanov Russian University of Economics \\ Russian Federation, 117997, Moscow, Stremyanny lane, 36 \\ E-mail: ju.lis@list.ru
}

\title{
DIGITALIZATION OF ECONOMICS AND XBRL IN THE EXCHANGE OF FINANCIAL INFORMATION IN THE BUSINESS COMMUNITY
}

Summary. The article studies the development of the digital economy in the Russian Federation and the introduction of the XBRL format for the exchange of business data in the business community and regulators. The study confirmed the relevance and relevance of the digital economy for the development of the economy as a whole. It is determined that the digital economy is a model of interaction of all participants in economic processes, based on the use of modern electronic communication channels and methods of recording and storing information using electronic document management. It was noted that the advanced technology to which XBRL belongs opens up new opportunities by proposing a new model that meets the changing needs of business information sharing.

Keywords: digital economy, digitalization, XBRL, exchange of financial information. 